\title{
Varicella zoster virus infections in Canadian children in the prevaccine era: A hospital-based study
}

\author{
Susan Kuhn MD, H Dele Davies MD, Taj Jadavji MD
}

\begin{abstract}
S Kuhn, HD Davies, T Jadavji. Varicella zoster virus infections in Canadian children in the pre-vaccine era: A hospital-based study. Can J Infect Dis 1997;8(6):323-328.

OBJECTIVE: To describe the clinical course of children admitted for varicella zoster virus (VZV) infections to a pediatric hospital before the release of VZV vaccine in Canada.

DESIGN: Retrospective case series.

SETTING: Tertiary pediatric hospital. Population studied was children aged 18 years or younger admitted to hospital between 1983 and 1992 who were discharged with a diagnosis of varicella or zoster. Of the 201 children who were identified, 36 were excluded, leaving 165 for analysis.

RESULTS: There was a male:female ratio of $1.5: 1$ and a median age of 5.3 years (range two weeks to 18 years). The group included those who were previously healthy $(70,42.4 \%)$, immunocompromised $(60,36.4 \%)$, and those with nonimmunocompromising conditions $(35,21.2 \%)$. Comparison of immunocompetent and immunocompromised children revealed that complication of VZV infection was a more common reason for admission among the former $(86$ of $105,81.9 \%$, $\mathrm{P}<0.001)$, whereas treatment with acyclovir to limit dissemination was the most common reason in the latter $(53$ of 60 , $88.3 \%, \mathrm{P}<0.001)$. Skin and soft tissue infections were the most common complications in immunocompetent children (36 of 98 ) and those younger than five years (26 of 53), whereas pulmonary complications predominated among immunocompromised patients (eight of 98) and neurological complications in five- to 10-year-olds (16 of 36). Only one death $(0.6 \%)$ occurred in an immunocompetent patient. Group A beta-hemolytic streptococci and Staphylococcus aureus caused equal numbers of secondary infections (92\% of all isolates).

CONCLUSIONS: Complications of VZV infections and secondary prophylactic antiviral treatment of immunocompromised children explain the majority of hospitalizations in this institution, and can be monitored after VZV vaccine introduction. Complications vary significantly with underlying healthy status and age.
\end{abstract}

Key Words: Childhood, Complications, Varicella zoster infections

\section{Infections au virus varicella-zona chez les enfants canadiens à l'époque prévaccinale : étude menée dans les hôpitaux}

OBJECTIFS : Décrire l'évolution clinique des enfants admis pour des infections au virus varicella-zona dans un hôpital pédiatrique avant la mise en marché d'un vaccin anti-VZV au Canada.

MODÈLE : Série de cas rétrospectifs.

CONTEXTE : Hôpital pédiatrique de soins tertiaires. La population étudiée regroupait des enfants de 18 ans ou moins

Departments of Pediatrics and Medical Microbiology and Infectious Diseases, and The Child Health Research Unit, Alberta Children's Hospital, University of Calgary, Calgary, Alberta

Correspondence and reprints: Dr Susan Kuhn, Alberta Children's Hospital, 1820 Richmond Road SW, Calgary, Alberta T2T 5C7. Telephone

403-229-7211, fax 403-229-7649

Received for publication November 5, 1996. Accepted March 27, 1997 
admis à l'hôpital entre 1983 et 1992 et qui ont obtenu leur congé avec un diagnostic de varicelle ou de zona. Parmi les 201 enfants qui ont été identifiés, 36 ont été exclus, ce qui en laissait 165 pour l'analyse.

RÉSULTATS : Le ratio hommes-femmes était de 1,5 2.1 et l'âge moyen était de 5,3 ans (variant de deux semaines à 18 ans). Le groupe comprenait les sujets auparavant en bonne santé $(70,42,4 \%)$, des sujets immunodéprimés (60, $36,4 \%$ et des sujets présentant des maladies sans immunodépression $(35,21,2 \%)$. La comparaison entre les enfants immunocompétents et immunodéprimés a révélé que la complication de l'infection au VZV était une raison plus fréquente d'admission chez le premier groupe ( 86 sur 105, 81,9\%, P < 0,001) alors que le traitement à l'acyclovir pour limiter la dissémination de l'infection a été la raison la plus fréquente dans le dernier groupe ( 53 sur $60,88,3 \%, \mathrm{P}<0,001$ ). Les infections de la peau et des tissus mous ont été les complications les plus courantes chez les enfants immunocompétents (36 sur 98) et chez les sujets de moins de cinq ans (26 sur 53), alors que les complications pulmonaires ont prédominé chez les patients immunodéprimés ( 8 sur 98) et les complications neurologiques chez les 5 à 10 ans (16 sur 36 ). Un seul décès $(0,6 \%$ est survenu chez un patient immunocompétent. Les streptocoques bêta-hémolytiques du groupe A et Staphylococcus aureus ont provoqué un nombre égal d'infections secondaires ( $92 \%$ de tous les isolats).

CONCLUSIONS : Les complications des infections à VZV et le traitement antiviral prophylactique secondaire des enfants immunodéprimés expliquent la majorité des hospitalisations dans cet établissement et peuvent être surveillées après l'introduction du vaccin anti-VZV. Les complications varient considérablement selon l'état de santé sous-jacent et l'âge.

$\mathrm{V}$ aricella zoster virus (VZV) infection is a common pediatric illness with a broad spectrum of severity. Although the vast majority of affected children experience a benign course, one of every 1000 cases of chickenpox is estimated to require hospitalization (1). There is only one study examining children hospitalized with VZV infections since acyclovir became available (2), and it is restricted to previously healthy children admitted because of a complication of varicella. Recent information about other pediatric patient populations and reasons for admission related to VZV infections is lacking. Varicella vaccine was recently released in United States, and licensure is anticipated soon in Canada. We designed a retrospective study to describe the clinical course and outcome of patients admitted to our institution to allow monitoring of the impact of vaccine introduction.

\section{METHODS}

Patient profile: The Alberta Children's Hospital, Calgary, Alberta (ACH) is a 144-bed university-affiliated primary, secondary and tertiary care centre serving a population of 1.2 million in southern Alberta, southwestern British Columbia and southeastern Saskatchewan. On average, there are about 6500 admissions per annum to the institution. The health records of all patients 18 years of age or younger who presented with varicella infection between January 1, 1983 and December 31, 1992 were reviewed. Included in the study were all patients with a discharge diagnosis of varicella, zoster, and/or Reye's syndrome. Cases were excluded if the child developed varicella after admission and did not require any supportive or specific therapy. In most of these cases, the child had been admitted for an elective surgical procedure and was discharged immediately upon diagnosis of VZV infection. A standardized data collection form was used to extract the following information from health records: age; sex; primary or reactivated VZV infection; presence of underlying immune defect (including any malignancy, organ transplantation or condition being treated with immunosuppressive corticosteroid doses) or nonimmunocompromising condition (any condition leading to multiple investigations, hospitalizations and/or physician visits, including those on replacement doses of corticosteroids, ie, less than $15 \mathrm{mg} / \mathrm{m}^{2} /$ day methylprednisolone); investigations including complete blood count and viral/bacterial culture; com- plications(s) including location(s), etiology and treatment; dose, route and duration of antiviral and antibacterial medication; and outcome. A bacterial infection might have been suspected on clinical grounds and was confirmed by isolation of a bacterial pathogen. A confirmed infection was 'invasive' if the organism was isolated from blood, cerebrospinal fluid or joint aspirate, and 'noninvasive' if the culture site was a skin lesion. Possible outcomes included morbidity (a new permanent deficit or a temporary deficit requiring treatment at discharge) and mortality.

Data analysis: Data gathered on patients was entered into Access (Microsoft, Washington), a database program. Differences in proportions were tested using a two-sided Fischer's exact test, or ${ }^{2}$ test for r-by-2 tables. A ${ }^{2}$ test for trend was used to detect trends over time. All statistical calculations were performed on EPI Info version 6.0 (Centers for Disease Control and Prevention, Georgia) on an IBM-compatible PC; $\mathrm{P}<0.05$ was considered statistically significant.

\section{RESULTS}

Two hundred and one children were identified, of whom 36 $(17.9 \%)$ were excluded due to hospitalization for other reasons, leaving 165 (82.1\%) evaluable. There were 2.6 varicella infections for every 1000 admissions to $\mathrm{ACH}$ over the study period (range 1.2 to 4.5); however, the number of cases per 1000 admissions increased significantly during the study $(\mathrm{P}<0.01)$.

Demographic characteristics and clinical presentation are shown in Table 1. The proportion of immunocompromised patients increased from $28.1 \%$ in the first five years to $40.0 \%$ in the last five years $(\mathrm{P}=0.13)$. All patients admitted with zoster (16) were either immunocompromised (13 of $60,21.7 \%$ ) or had a nonimmunocompromising condition (three of $35,8.6 \%$; difference $\mathrm{P}=0.15$ ).

Three major reasons for hospitalization were identified (Figure 1). Treatment of complication of VZV infection was the most common $(92,55.8 \%)$ followed by antiviral therapy to prevent dissemination $(62,37.6 \%)$ and supportive care only (11, $6.7 \%$ ), but differed significantly by underlying patient health status (Figure 1). The relative frequency of admission for each indication was stable over the study period $(\mathrm{P}=0.6)$.

One hundred and seven complications occurred in 92 pa- 
TABLE 1

Demographics and presentation in 165 children admitted with varicella zoster virus (VZV) infection

\begin{tabular}{lc}
\hline Characteristics & Number $(\%)$ \\
\hline Male & $98(59.4)$ \\
Age* & \\
Under 5 years & $80(48.5)$ \\
5 to 10 years & $63(38.2)$ \\
Over 10 years & $12(7.3)$ \\
Clinical status & \\
Healthy & $70(42.4)$ \\
Nonimmunocompromising condition & $35(21.1)$ \\
Immunocompromising condition & $60(36.4)$ \\
VZV infection & \\
Varicella & $149(90.3)$ \\
Zoster & $16(9.7)$ \\
\hline
\end{tabular}

*Median 5.3 years, range two weeks to 18 years

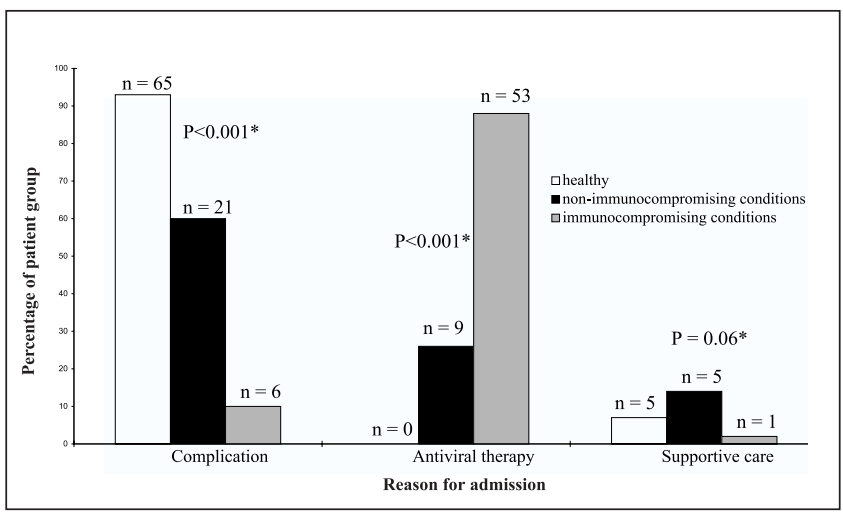

Figure 1) Reason for admission to hospital with varicella zoster infections by patient health status. Nonimmunocompromising conditions include eight endocrinopathies (two panhypopituitarism, two congential adrenal hyperplasia, four insulin-dependent diabetes mellitus), six skin disorders (four eczema, one burn, one lamellar icthyosis), four seizure disorders, four congential heart disorders, three asthmatics, three infants born prematurely, portal hypertension, polycystic kidneys, recurrent severe emesis of unknown etiology, chronic idiopathic thrombocytopenic purpura, chromosomal anomaly, cystic fibrosis and mononucleosis. Immunocompromising conditions include acute lymphocytic leukemia (22), acute myeloblastic leukemia (one), lymphoma (three), solid tumour (12), immunosuppressive doses of steriods for nonmalignant conditions (16), bone marrow transplant (two), liver transplant (one), hypogammaglobulinemia/neutropenia (one), ataxia-telangiectasis (one) and neonate (one). *Comparisons made between immunocompetent (healthy and nonimmunocompromised conditions) and immunocompromised patients. Chronic skin disease (one of each eczema, lamellar icthyosis), V-1 zoster with underlying portal hypertenion (one), endocrinopathies for which replacement doses of corticosteriods were given (four), and congential heart disease (two)

tients (Table 2). Skin and soft tissue infections, joint infections, and neurological, pulmonary and hepatic complications comprised 79 of 107 (73.8\%) of the total, although anatomical site of complication varied by underlying health status (Figure 2). Of those with 'other' types of complications, exacerbation of an underlying condition occurred in seven (29.2\%) children with a nonimmunocompromising condition.

Twenty-three bacterial pathogens were isolated from 20
TABLE 2

Summary of complications noted on admission in 92 children hospitalized with varicella zoster virus (VZV) infections

\begin{tabular}{|c|c|c|}
\hline Complications & $\begin{array}{l}\text { Nonimmuno- } \\
\text { compromised }^{*}\end{array}$ & $\begin{array}{l}\text { Immuno- } \\
\text { compromised }\end{array}$ \\
\hline Skin and soft tissue (total) & 36 & 0 \\
\hline Infected pox/cellulitis & 35 & 0 \\
\hline Abscess & 1 & 0 \\
\hline Neurological (total) & 27 & 0 \\
\hline Encephalitis & 11 & 0 \\
\hline Cerebellitis & 9 & 0 \\
\hline Drug-encephalopathy & 3 & 0 \\
\hline Meningitis $^{+}$ & 2 & 0 \\
\hline Febrile seizure & 1 & 0 \\
\hline Cerebral herniation & 1 & 0 \\
\hline Pulmonary (total) & 8 & 4 \\
\hline VZV pneumonitis ${ }^{\ddagger}$ & 2 & 4 \\
\hline Bacterial pneumonia $^{\ddagger}$ & 4 & 0 \\
\hline Viral croup & 2 & 0 \\
\hline Septic arthritis (total) & 2 & 0 \\
\hline VZV hepatitis (total) & 0 & 2 \\
\hline Other (total) & 25 & 3 \\
\hline Diabetic ketoacidosis ${ }^{\S}$ & 4 & 0 \\
\hline Acute otitis media & 3 & 1 \\
\hline Scarlet fever & 4 & 0 \\
\hline Dehydration $\left(1^{\S}\right)$ & 5 & 0 \\
\hline Bacteremia & 1 & 1 \\
\hline Henoch-schonlein purpura & 2 & 0 \\
\hline $\begin{array}{l}\text { Idiopathic thrombo- } \\
\text { cytopenic purpura }\end{array}$ & 1 & 0 \\
\hline Stress ulcer & 1 & 0 \\
\hline $\begin{array}{l}\text { Staphylococcus pyogenes } \\
\text { pharyngitis }\end{array}$ & 1 & 0 \\
\hline Congestive heart failure ${ }^{\S}$ & 1 & 0 \\
\hline Conjunctivitis & 1 & 0 \\
\hline Acute asthmatic episode ${ }^{\S}$ & 1 & 0 \\
\hline Nephrotic syndrome & 0 & 1 \\
\hline Total complications ${ }^{\pi}$ & 98 & 9 \\
\hline
\end{tabular}

*Included children who were healthy or had a nonimmunocompromising condition; ${ }^{\dagger}$ Etiology presumed viral (1), confirmed Haemophilus influenzae (1); ${ }^{*}$ Distinguished on the basis of documented clinical, radiological, and bacteriologic findings; ${ }^{\S}$ Exacerbation of an underlying condition in seven patients; "Total number greater than the 92 patients because some patients had more than one complication

(40.8\%) of the 49 children suspected of having a secondary bacterial infection. Twenty-one (91.3\%) of the isolates were either Staphylococcus aureus (10) or Staphylococcus pyogenes (11), with neither organism increasing in relative frequency over time in years $(\mathrm{P}=0.11)$. Invasive infections occurred with both $S$ aureus (2) and $S$ pyogenes (3). Streptococcus pneumoniae pneumonia (1) and Haemophilus influenzae type B meningitis (in a one-year-old in 1984) were also noted.

Complication severity also varied with the presence of an underlying condition. Overall, disseminated VZV infection at the time of admission (including pneumonitis, hepatitis or both) occurred in five of $60(8.3 \%)$ immunocompromised patients compared with two of 105 (1.9\%) immunocompetent pa- 


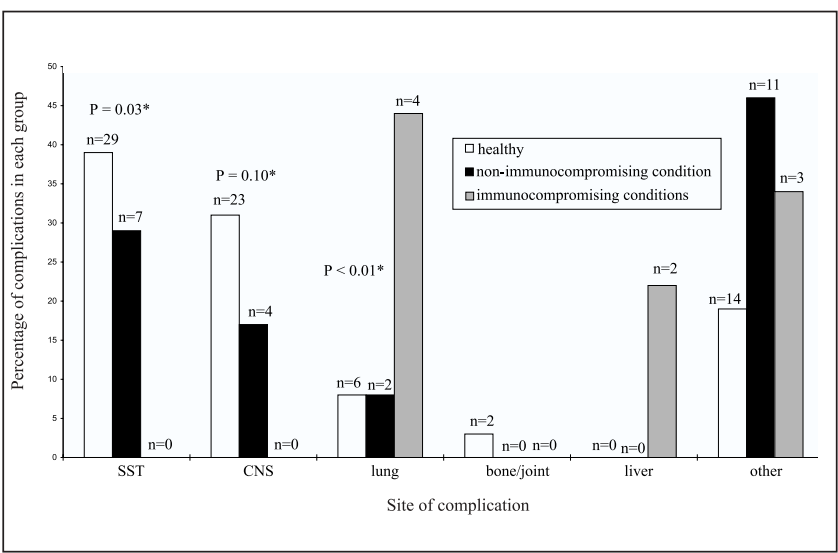

Figure 2) Sites of varicella zoster virus complications leading to admission, by patient health status group. *Comparisons made between immunocompetent (healthy and nonimmunocompromising conditions) and immunocompromised patients. CNS Neurological complications; SST Skin and soft tissue infection

tients $(\mathrm{P}=0.10)$. If only children with complications at admission are considered, immunocompromised patients had more severe complications than immunocompetent patients as measured by disseminated VZV (five of six versus two of 86 , $\mathrm{P}<0.001$ ) and two or more complications (three of 60 versus 12 of $86, \mathrm{P}=0.05$ ).

Frequency of complication on admission decreased with increasing age, occurring in 53 of $80(66.3 \%)$ children under five years of age and 36 of $64(56.3 \%)$ of five- to 10-year-olds compared with three of $21(14.3 \%)$ of those over 10 years. However, children over ten years of age were more likely to be immunocompromised (15 of 21,71.4\%) compared with those 10 years of age or younger ( 45 of $144,31.3 \%$; $<<0.0001$ ). Patient age also appeared to be related to complication site (Figure 3).

Use of antiviral therapy in absence of viral dissemination occurred only in children with underlying medical conditions (Figure 1). Of the nine children $(25.7 \%)$ with a nonimmunocompromising condition who received antiviral medication, four had endocrinopathies and received replacement doses of corticosteroids, two had congenital heart disease, two had chronic skin disease (eczema, lamellar icthyosis) and one had portal hypertension (with noncorneal V-1 zoster).

Among immunocompromised patients who received antiviral therapy for any reason, the route and duration of treatment varied. Forty-eight (80.0\%) were given antiviral therapy (acyclovir in all but one case who received vidarabine) intravenously only for a mean duration of 5.4 days. Those with complications (five of 48) received a longer duration compared with those without complications (7.6 versus 5.2 days). Acyclovir, intravenous adminstration followed by oral, was given in eight uncomplicated cases (13.3\%) for a mean of eight days (four days each intravenous and oral). One patient with zoster received five days of oral acyclovir alone. Two patients with solid tumours and zoster and one with nephrotic syndrome and varicella/peritonitis did not receive antiviral therapy.

Morbidity and mortality were low both overall and by subgroups (Table 3).

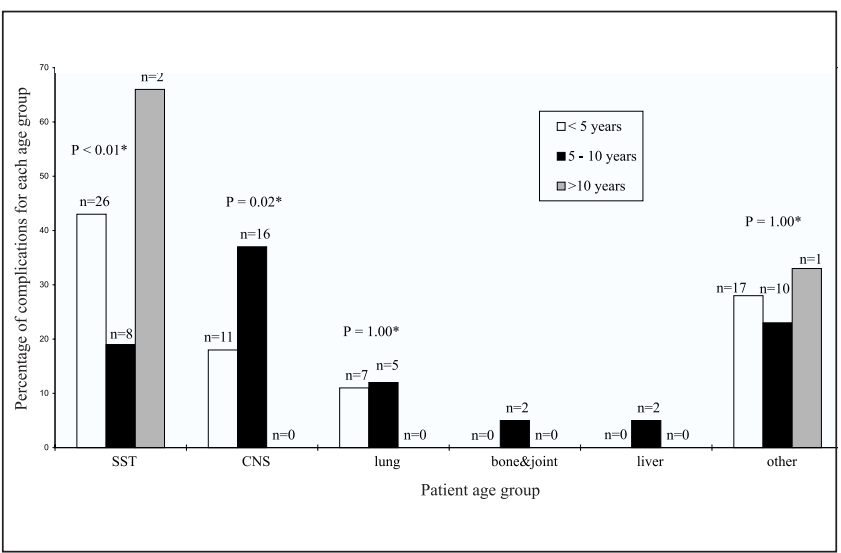

Figure 3) Anatomical sites among patients with complications by patient age group. *Comparisons were made between children younger than five years of age and children aged five to 10 years, given the small number of children older than 10 years of age. CNS Neurological complications; SST Skin and soft tissue infection

\section{DISCUSSION}

This hospital-based study describes the epidemiology of immunocompromised and immunocompetent children admitted with VZV infection before the vaccine era. Study populations reported in two other publications since $1980(2,3)$ differ from ours, with one being conducted before the licensure of acyclovir (3) and the other including only immunologically normal children (2). Immunocompromised patients accounted for less than $20 \%$ of all pediatric hospitalizations in the 1981 study (3), contrasting with $36 \%$ in our population. A study based on data from an American health maintenance organization noted 21 pediatric hospital admissions but did not include information about underlying conditions (4). The majority of the increase in the annualized VZV admissions over the 10-year period was accounted for by immunocompromised children, suggesting that this population has either increased relative to nonimmunocompromised patients and/or has become more likely to be admitted for acyclovir therapy.

Although occasionally noted as a subgroup of immunologically normal children $(2,3)$, those with a nonimmunocompromising condition have not previously been examined as a specific group of interest. In our population, they made up one-fifth of all pediatric VZV admissions. This group was intermediate between healthy and immunocompromised children in their relative frequency of admissions for treatment of complications and use of acyclovir to prevent dissemination.

Treatment of complications was the most frequent reason for children to be admitted to hospital with VZV infections. As in previous studies, skin and soft tissue infections predominated (1-3), followed by neurological complications. Reye's syndrome was not identified in any of our patients, consistent with recent studies showing that the latter complication was decreasing (2) or absent (4) by 1990. As expected, the severity appeared to be greatest among the immunocompromised children.

Half of all the complications necessitating admission in this study were the result of a bacterial infection. $S$ pyogenes and $S$ aureus were equally likely to cause invasive infections 
TABLE 3

Outcome of patients admitted with varicella zoster virus (VZV) infection

\begin{tabular}{|c|c|c|c|c|}
\hline Outcome & Healthy $(n=70)$ & $\begin{array}{c}\text { Patient subgroup } \\
\text { Nonimmunocompromising } \\
\text { condition }(n=35)\end{array}$ & $\begin{array}{l}\text { Immunocompromised } \\
\qquad(n=60)\end{array}$ & All patients $(n=165)$ \\
\hline Median (days) & 3.5 & 5.0 & 6.0 & 5.0 \\
\hline Range (days) & $1-78$ & $1-159$ & $1-128$ & $1-159$ \\
\hline Morbidity & $2 *$ & $1^{\dagger}$ & 0 & $3(1.8 \%)$ \\
\hline
\end{tabular}

*Postpneumonia pneumatoceles (1); Neurological deficit post-Haemophilus influenzae meningitis; ${ }^{\dagger}$ New oxygen requirement in previously stable bron-

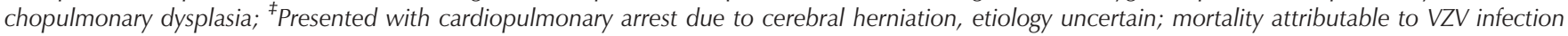
equals 1.6 per 100,000 admissions for any reason

during the 10 years reviewed. Other studies have shown that one or the other usually predominates $(3,5)$. Invasive $S$ pyogenes infections have been of particular concern recently $(6,7)$, with risk of varicella estimated to be almost 40 times that of the general population (8). Notably, skin and soft tissue superinfections did not occur in the immunocompromised group despite that this group was not given antibiotics empirically. This may be due in part to age differences (immunocompromised patients were older than immunocompetent children and therefore may be less likely to have skin and soft tissue infection) and the rapid institution of acyclovir for VZV infection in most of these patients.

Complications as a reason for admission in children increased with decreasing age and varied in type and location across different age categories. Because the majority of varicella infections occur in children under 10 years (9), the absolute number of complications would also be expected to be highest in this age group. A bias towards admission of younger VZV-infected patients to ACH compared with two other institutions in the city (with a total of 40 pediatric beds during the study period versus 144 beds at $\mathrm{ACH}$ ) could also account for this, although there is no evidence to support this. One previous population-based study found that proportionately more adolescents and adults get complications with varicella than children; adult complications consist mostly of neurological abnormalities, whereas skin and soft tissue infections were most common in the youngest age group (less than five years) (1). While authors have speculated that younger children may be more prone to secondary bacterial infection (3), a recent community-based study found that skin and soft tissue infections might occur as frequently in older pediatric patients (4). A greater likelihood of hospitalization for bacterial superinfection in the preschool age group may explain the apparent higher frequency of such complications in hospital-based studies such as this one.

Antiviral therapy for uncomplicated VZV infection was also a common reason for admission, not only among the immunocompromised, but also in some children with nonimmunocompromising conditions. Use of acyclovir for those with either cardiac disease or on physiological replacement doses of corticosteroids suggested an underlying concern about more severe manifestations in these patient populations. Exacerbation of conditions such as insulin-dependent diabetes mellitus (3) and cystic fibrosis $(10,11)$ due to varicella have been noted previously. These findings suggest that there may be real or perceived reasons other than immunocompromising conditions that place children at increased risk of severe or complicated VZV infection. Whether this is true and these children warrant treatment with acyclovir remains to be demonstrated.

Acyclovir was predominately used for prevention of dissemination in immunocompromised patients. Although the mean duration of treatment was shorter than recommended by some authorities (12), in several cases where intravenous and oral acyclovir were used sequentially, no relapses occurred. Others have reported treatment with oral acyclovir in a similar population (13), but this is not considered standard therapy. Patients with complications did receive a longer course of antiviral treatment compared with those without complications.

Previous reviews of varicella in children have found a low mortality rate with figures ranging from a population-based estimate of two deaths per 100,000 cases of varicella (14) to $1 \%$ in hospitalized cases (2). Although our study differs from the latter (2) because of the inclusion of immunocompromised children, the mortality rate $(0.6 \%)$ was similar. Given the improved outcome with antiviral treatment (15), this figure likely reflects the use of antiviral medications in the majority of patients in this group. In this study, we demonstrate that VZV infection remains a significant cause of hospitalization and morbidity in our population in the prevaccine era. Previous studies have shown the cost and benefits of immunizing healthy children against VZV $(16,17)$. Vaccine efficacy is estimated to be $90 \%$ (18) or more (19) in immunocompetent hosts and similar in leukemic children who seroconvert (20). Thus, the vaccine would be expected to prevent the majority of wild type varicella cases, particularly if most children are immunized before becoming immunocompromised. Even with a higher vaccine failure rate in immunocompromised children vaccine failure rates range from $10 \%$ to $90 \%$ - an economic evaluation of varicella vaccine before pediatric liver and kidney transplantation was able to demonstrate a net savings (21). Based on the results of this study, we would expect significant savings would result from fewer hospitalizations and therefore a reduction in acyclovir use in immunocompromised children.

While zoster still occurs postimmunization, it appears to 
happen less frequently than after wild type infection (22). In the long term, a mathematical model of VZV vaccine effectiveness predicts that after 10 years with $70 \%$ coverage, the number of VZV cases would drop to less than $30 \%$ of prevaccine numbers of cases, and would virtually cease altogether with $97 \%$ coverage (23).

\section{CONCLUSIONS}

Before the introduction of the varicella vaccine, secondary complications were the most common reason for a child to be admitted to this hospital with a VZV infection. Complications varied with underlying condition and age. Subgroup analyses

ACKNOWLEDGEMENTS: Dr Kuhn was supported, in part, by the Canadian Infections Diseases Society Glaxo Fellowship Award at the time this study was conducted. Dr Davies is supported through a Clinical Investigatorship Award of the Alberta Heritage Foundation for Medical Research

\section{REFERENCES}

1. Guess HA, Broughton DD, Melton JG, Kurland LT. Population-based studies of varicella complications. Pediatrics 1986;78:723-7.

2. Jackson MA, Burry VF, Olson LC. Complications of varicella requiring hospitalization in previously healthy children. Pediatr Infect Dis J 1992;11:441-5.

3. Fleisher G, Henry W, McSorley M, Arbeter A, Plotkin S. Life-threatening complications of varicella. Am J Dis Child 1981;13:896-9.

4. Choo PW, Donahue JG, Manson JE, Platt R. The epidemiology of varicella and its complications. J Infect Dis 1995;172:706-12.

5. Bullowa JGM, Wishik SM. Complications of varicella I: their occurrence among 2534 patients. Am J Dis Child 1935;49:923-6.

6. Peterson CL, Vugia DJ, Meyers HB, et al. Risk factors for invasive group A streptococcal infections in children with varicella: A case-control study. Pediatr Infect Dis J 1996;15:151-6.

7. Davies HD, Matlow A, Scriver SR, et al. Apparent lower rates of streptococcal toxic shock syndrome and lower mortality in children with invasive group A streptococcal infections compared with adults. Pediatr Infect Dis J 1994;13:49-56.

8. Davies HD, McGeer A, Schwartz B, et al. A prospective, population-based study of invasive group A streptococcal infections, including streptococcal toxic shock syndrome and the risk of disease transmission. N Engl J Med 1996;335:547-54.

9. Preblud SR. Age-specific risks of varicella complications. Pediatrics 1981;68:14-7.

10. Ong EL, Mulvenna P, Webb KA. Varicella-zoster infection in adults with cystic fibrosis: Role of acyclovir. Scand J Infect Dis 1991;23:283-5.

11. MacDonald NE, Morris RF, Beaudry PH. Varicella in children with cystic fibrosis. Pediatr Infect Dis J 1987;6:414-6.

12. Infectious Diseases and Immunization Committee, Canadian showed that the most common reason for admission included bacterial superinfections in nonimmunocompromised children and early antiviral therapy in immunocompromised children. With certain nonimmunocompromising conditions, even though they are not noted in current recommendations $(12,24)$, there was a perception of increased risk resulting in a decision to treat with acyclovir in the absence of known complications. A universal varicella vaccination program would be expected to lead to reduced circulation of wild type virus and infections, resulting in fewer VZV-related admissions in both immunocompromised and immunocompetent children, and can be monitored after introduction of VZV vaccine.

Paediatric Society. Chickenpox: Prevention and treatment. Can J Paediatr 1994;1:88-93.

13. Meszner Z, Nyerges G, Bell AR. Oral acyclovir to prevent dissemination of varicella in immunocompromised children. J Infect 1993;26:9-15.

14. Preblud SR, Orenstein WA, Bart KJ. Varicella: Clinical manifestations, epidemiology and health impact in children. Pediatr Infect Dis 1984;3:505-9.

15. Prober CG, Kirk LE, Keeney DO. Acyclovir therapy of chickenpox in immunosuppressed children - A collaborative study. J Pediatr 1982;101:622.

16. Lieu TA, Cochi SL, Black SB, et al. Cost-effectiveness of a routine varicella vaccination program for US children. JAMA 1994;271:375-81.

17. Preblud SR. Varicella: Complications and costs. Pediatrics 1986;78(Suppl):728-35.

18. White CJ, Kuter BJ, Hildebrand CS, et al. Varicella vaccine (VARIVAX) in healthy children and adolescents; results from the clinical trials, 1987 to 1989 . Pediatrics 1991;87:604-10.

19. Weibel RE, Kuter BJ, Neff BJ, et al. Live Oka/Merck varicella vaccine healthy children. JAMA 1985;254:2435-9.

20. Gershon AA, LaRussa P, Steinberg S. Live attenuated varicella vaccine: Current status and future uses. Semin Pediatr Infect Dis 1991:2:171-8.

21. Kitai IC, King S, Gafni A. An economic evaluation of varicella vaccine for pediatric liver and kidney transplant recipients. Clin Infect Dis 1993;17:441-7.

22. Hardy IB, Gershon A, Steinberg SP, LaRussa P, Varicella Vaccine Collaborative Study Group. The incidence of zoster after immunization with live attenuated varicella vaccine. A study in children with leukemia. N Engl J Med 1991;325:1545-50.

23. Halloran ME, Cochi SL, Lieu TA, Wharton M, Fehrs L. Theoretical epidemiologic and morbidity effects of routine varicella immunization of preschool children in the United States. Am J Epidemiol 1994;140:81-104.

24. Committee on Infectious Diseases, American Academy of Pediatrics. The use of oral acyclovir in otherwise healthy children with varicella. Pediatrics 1993;91:674-6. 


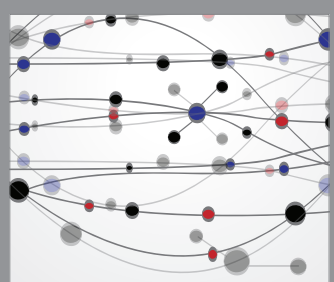

The Scientific World Journal
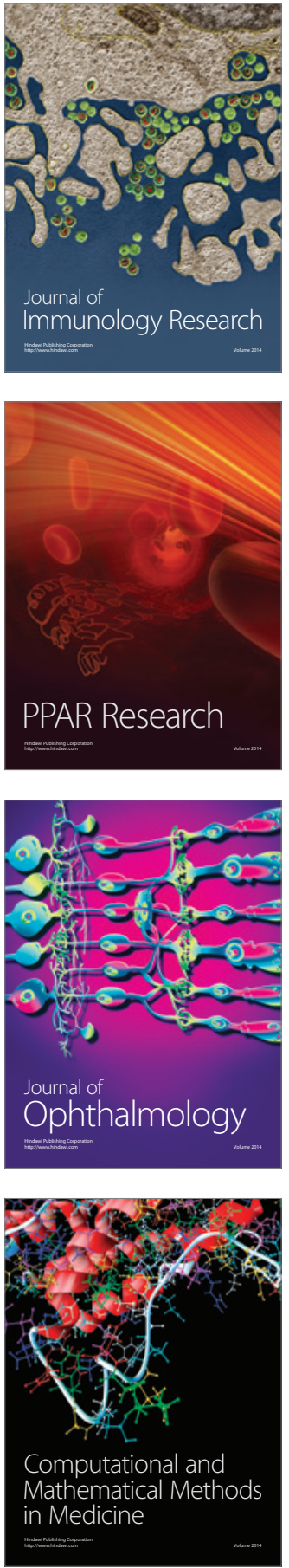

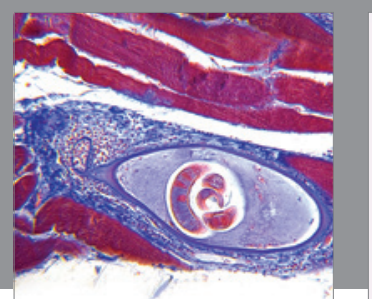

Gastroenterology Research and Practice

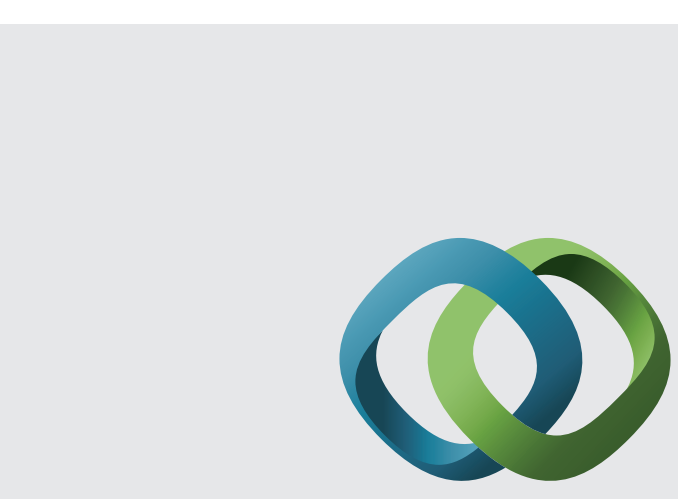

\section{Hindawi}

Submit your manuscripts at

http://www.hindawi.com
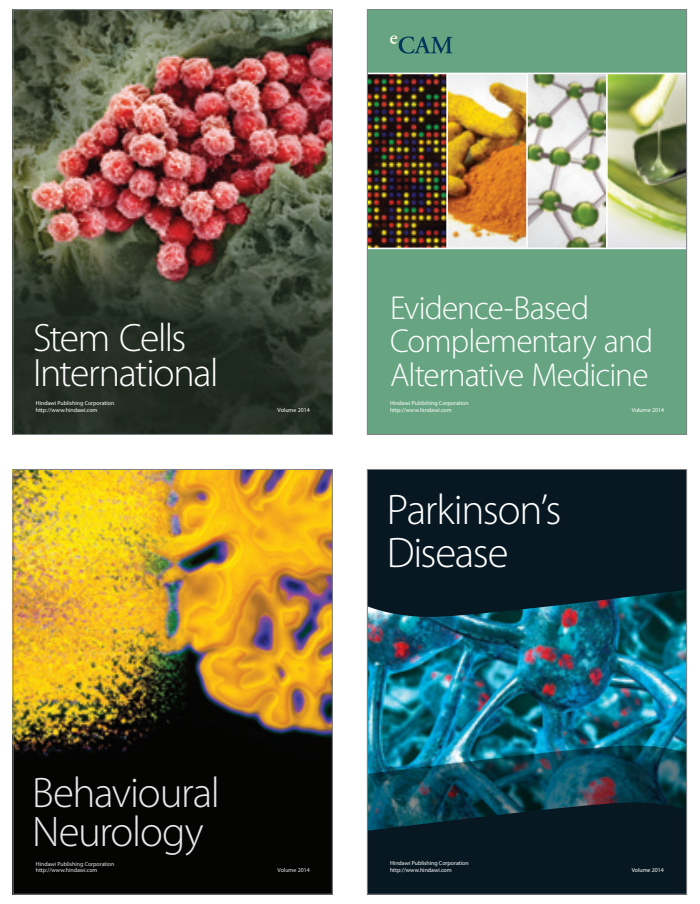
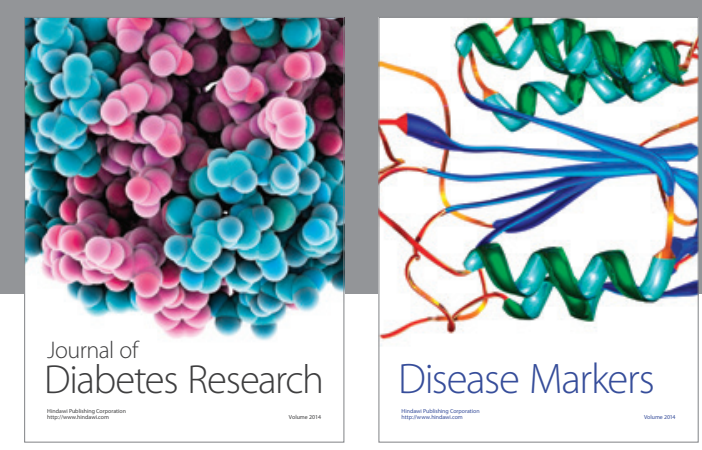

Disease Markers
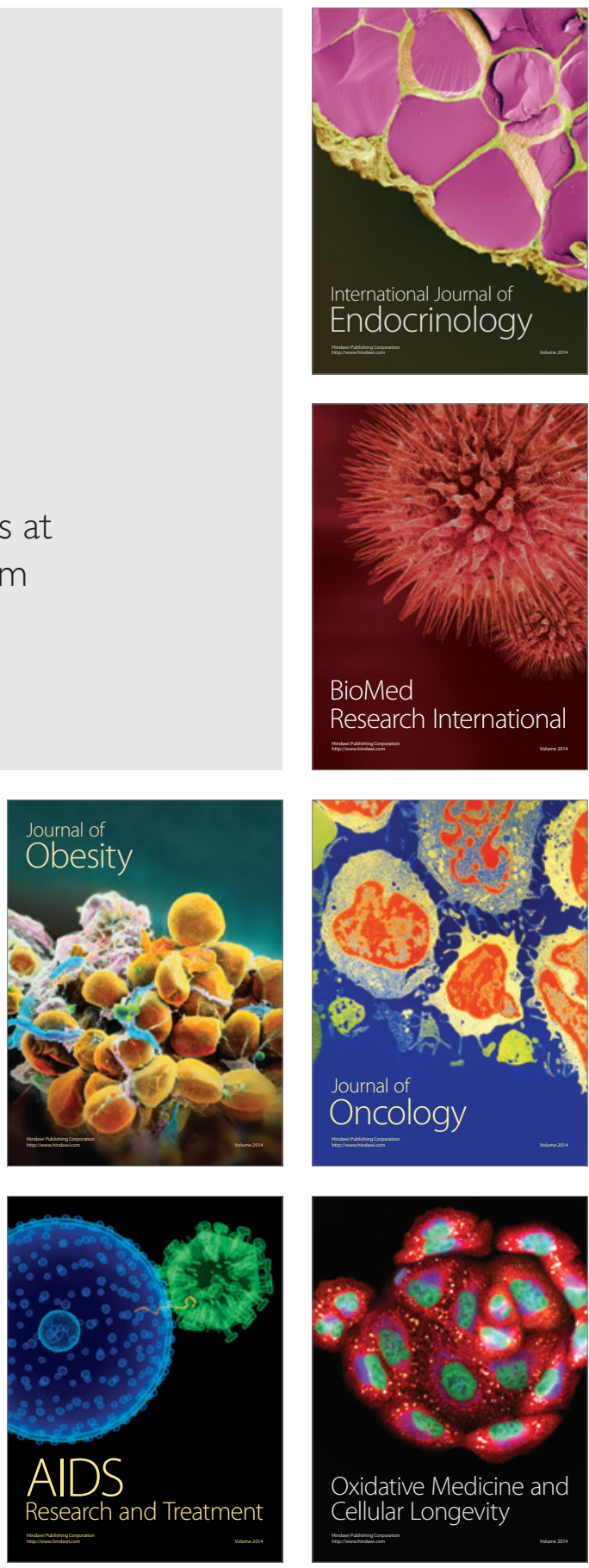